\title{
The Method of Braille Embossed Dots Segmentation for Braille Document Images Produced on Reusable Paper
}

\author{
Sasin Tiendee ${ }^{1}$, Charay \\ Lerdsudwichai ${ }^{2}$ \\ Department of Computer Engineering \\ Faculty of Engineering, Kasetsart \\ University \\ Bangkok, Thailand
}

\author{
Somying Thainimit ${ }^{3}$ \\ Department of Electrical Engineering \\ Faculty of Engineering, Kasetsart \\ University \\ Bangkok, Thailand
}

\author{
Chanjira Sinthanayothin ${ }^{4}$ \\ National Electronics and Computer \\ Technology Center \\ National Science and Technology \\ Development Agency \\ Pathum Thani, Thailand
}

\begin{abstract}
Braille is the language of communication for blind and visually impaired people. Braille characters are embossed at points to convey the meaning. Typically, Braille documents can be produced on plain paper. Braille documents can be created on reusable paper, also known as a third-page paper; this reduces the paper cost, allowing more available documents to stimulate learning for blind or visually impaired persons. This research presents a method of Braille embossed dots segmentation for Braille document images produced on reusable paper to support the availability of cheaper learning material. Initially, Braille documents were imported with a calibrated scanner, Braille document image layer separation was then performed. Followed by edge removal, Braille embossed dot recovery, noise removal, and specify the embossed Braille point. This research was conducted by using four scanners, which scanned Braille documents images under four different lighting conditions. For each lighting condition, the Braille document image area was cropped to the desired size, considering the possible event conditions. They were used to create over 200,000 Braille cells, with over 12 billion patterns. When calculating the average performance under all lighting conditions, the values were Precision 1.0000, Recall 0.7817, Accuracy 0.8545, and F-Measure 0.8756. By effectively using Braille embossed dots segmentation, the process of Braille document recognition will also be efficient.
\end{abstract}

Keywords-Braille; embossed dots; document images; reusable paper; segmentation; recognition; blind; visually impaired

\section{INTRODUCTION}

Louis Braille invented Braille so allowing blind or visually impaired persons to communicate using written communication; subsequently, there is a requirement they become proficient in writing and reading Braille. In Braille, one cell of Braille has six dots that represents a meaning. To create Braille documents is a writing pad (slate) and a sharp tip (stylus) being portable and cheap. Other devices can create Braille documents, such as a Braille typewriter and a Braille printer, but these devices are expensive and require expensive specialized paper. It is common practice that blind, or the visually impaired people produce Braille documents on reusable paper, known as the third page. These documents contain Braille embossed dots, characters, tables, and pictures known as patterns. It reduces the cost of purchasing Braille paper and is a cost-effective use of natural resources.

Braille documents created with reusable paper are everywhere. This research aims to accurately extract the Braille embossed dots [1-6] on those Braille document. Those Braille embossed dots are used for Braille recognition [7-12] and converted to characters. In the end, these characters will be used to make typical books.

Scope and limitations: This research created reusable papers with characters printed by using LaserJet and Inkjet printers on an A4 80 GSM thick. Braille documents were created on the reusable papers by using a portable Braille device and scanned with a flatbed scanner at 300 DPI resolution.

Contribution: (1) To develop a method for Braille embossed dots segmentation for Braille documents produced on reusable papers. (2) To reduce the complexity problems and cost of purchasing paper to create Braille documents. (3) To support improved communication channels between people.

The paper was organized: Section II summarizes the relevant research and describes the new approaches to this research. Section III explains the proposed method. The dataset, experimental design, evaluation, and discussion of the results are described in Section IV. Section V summarizes the results and discusses them. The final section, Section VI, outlines our future work.

\section{RELATED WORK}

The evolution of Braille document image processing is shown in Fig. 1. It is divided into two groups: (1) Group 1 document image processing for typical documents. (2) Group 2 document image processing of Braille documents created on plain paper for the visually impaired where the Braille characters have embossed dots.

Group 1 can be divided into 2 subgroups: (1) Subgroup 1 is documents created on plain paper without an overlaid pattern. There are relevant research topics such as text/non-text classification in online handwritten notes [16], the 2D chemical structures recognition in document images [17], detecting math

\footnotetext{
* Corresponding Author
} 
equations in scientific document images [18], the Arabic word recognition of historical documents images [19], the Vietnamese character recognition for verifying ID card [20], document zoning for document layout analysis [21], analysis of the structure of the musical document image [22], bibliographic reference extraction [23], extracting text and figure from document images $[24,25]$, document localization in natural scene images [26], and table detection and segmentation in document images [27]. (2) Subgroup 2 is created on plain paper and overlapped patterns. There are related research topics such as image restoration and segmentation of historical document images caused by ink bleeding [28-30], glare detection on captured document images [31], shadow removal on captured document images [32], and text segmentation from a highlighted area with colors [33].

Group 2 has one subgroup: Subgroup 1 is a Braille document created on plain paper without an overlaid pattern. There are related research topics such as Braille character extraction for Braille document images recognition [1-6], Braille document images recognition [7-12], Parameter estimation of a Braille document images [13, 14], and Recovering the Braille embossed point of an old Braille document [15].

When considering the document image processing diagram for Braille documents as shown in Fig. 1 and comparing it with Fig. 2. In Fig. 2, the area to the right of the red dash line is a new research topic that has not been researched previously. This research project deals with Braille embossed dot segmentation for Braille document images produced on reusable paper. It has an overlaid pattern, as shown in Fig. 3. Therefore, this research is classified in Subgroup 2 of Group 2.

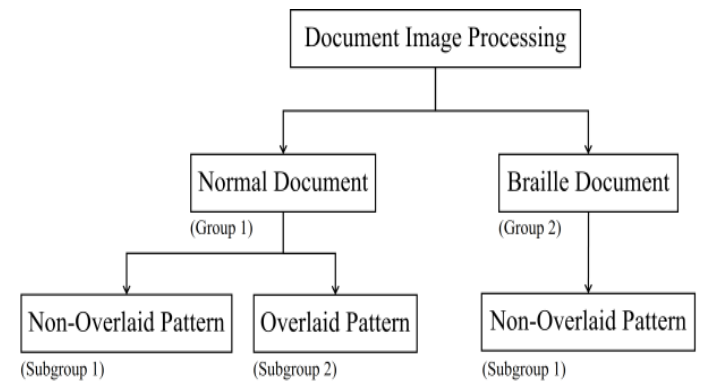

Fig. 1. The Diagram of Document Image Processing.

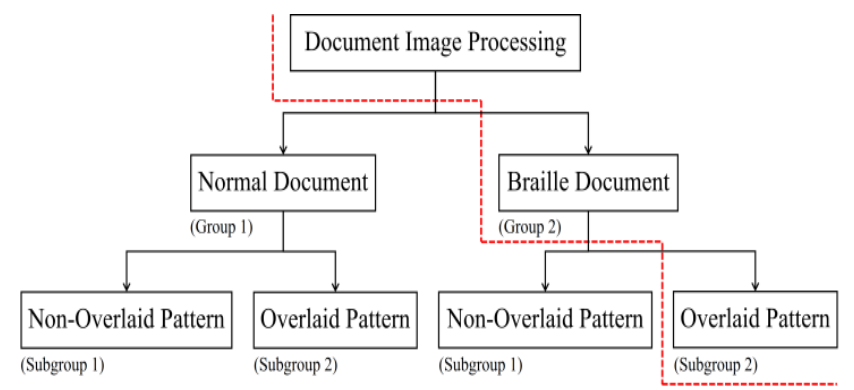

Fig. 2. The Diagram of the Document Image Processing with the Area to the Right of the Red Dash Line is a Research Topic that has not been previously Researched.

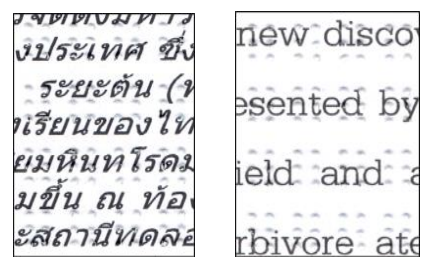

Fig. 3. Example of Braille Document Images Produced on Reusable Paper.

Subgroup 1 of Group 2 is related research: C. M. Ng et al. [1] used the Chain Code and grouped the Braille embossed dots into cells. A. Al-Saleh et al. [2], Braille document images modeled using Beta distribution for thresholding and used grid for Braille embossed dots segmentation. A. S. Al-Salman et al. [3] uses image enhancement and image rotation. Then a grid method is used to extract the Braille Cells. A.-S. Amany et al. [4] uses thresholding based on Beta distribution then creates a grid for dot detection. M. Y. Babadi et al. [5] perform skew correction and create grids for Braille cells segmentation. A. AlSalman et al. [6], this research use between-class variance with Gamma distribution to separate Braille embossed dots from the background. J. Mennens et al. [7], Braille documents are imported with a scanner. The mask and grid are used to extract the Braille embossed dots. L. Wong et al. [8], this research use techniques Half-Character Recognition then generate a grid to extract Braille embossed dots. L. Jie et al. [9, 10], this research uses Support Vector Machine (SVM), slides window techniques, and Haar wavelet to extract Braille embossed dots on Braille document images obtained from a scanner. B.-M. Hsu [11], this research used RCSA: Ratio Character Segmentation Algorithm for Braille embossed dots extraction. A. AlSalman et al. [12], the research use the Deep Convolution Neural Network (DCNN) for Braille document recognition. M. Yousefi et al. [13, 14], this research finds the parameters of Braille documents, skewness, scaling, line spacing to obtain Braille dots. H. Kawabe et al. [15] uses deep learning to classify Braille dots in long-preserved or ancient Braille documents. It can be seen that these studies focus on Braille documents created on plain paper only. There has been no research that has created Braille on reusable paper.

\section{PROPOSED METHOD}

This research proposed the method of Braille embossed dots segmentation for Braille document images. Braille documents were produced on reusable paper and plain paper. Flatbed scanners were used to scan the documents. The method comprises six steps as shown in Fig. 4. The first step was to perform a scanner calibration process using a specific calibration plate and calculating the edges' threshold values and the black areas. The second step was to perform a layer separation process by using the edges' threshold values and the black areas from the previous step. The third step was to perform the edge removal process by eliminating the edges. The fourth step was to perform the data recovery process by calculating the eroded mask's data to increase the Braille dots' details. The next step was to perform a noise removal process by applying an explosion algorithm to diffuse the black pixels and then to image enhancement by spatial filtering. The final process was to perform a Braille localization process by calculating the Braille dots' positions from the black pixels' positions. The details are as follows. 


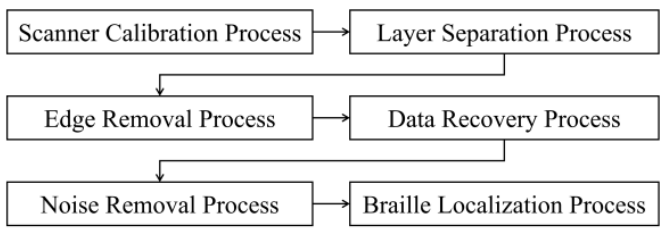

Fig. 4. The Diagram of Proposed Method.

\section{A. Scanner Calibration Process}

1) Plates for scanner calibration: The images were designed for scanner calibration, a black circle, and a black square then saved to the image files. Then printed on plain paper by using a laser printer and an inkjet printer is called the plates. Then, they were imported via a flatbed scanner.

2) The plates were converted to grayscale images: The plates were in the RGB color model. They were converted to the HSV color model. The color values of the V plane were applied to all three planes of the RGB color model. The grayscale images are shown in Fig. 5(a) and 5(b), comprising the black area in P-01 and the background in P-02.

3) Plate images are eroded with a mask: They were converted to binary images and then eroded with a small mask and large mask, respectively. As a result, it can be seen that the plate images were eroded by the small mask have a black area in P-03 of Fig. 5(c) and 5(d), are larger than the plate images eroded by the large mask, which have a black area in P-04 of Fig. 5(e) and 5(f).

4) Threshold values of the edges calculation: The plate images eroded by a small mask were compared with the plate image eroded by a large mask. The location of pixels with different color values in P-05 of Fig. 5(g) and 5(h), the color value of the grayscale image in Fig. 5(a) and 5(b) in that the position were stored in the array Edge, the threshold value for the edges of images was calculated by using the equation:

$$
\begin{aligned}
& T 1_{E d g e}=\operatorname{round}\left(\left(E d g e_{\text {mean }}+E d g e_{\min }\right) / 2\right) \\
& T 2_{E d g e}=\operatorname{round}\left(E d g e_{\text {mean }}+\text { sedge }\right) \\
& \text { sedge }=a b s\left(\left(E d g e_{\max }-E d g e_{\text {mean }}\right) / 2\right)
\end{aligned}
$$

where $T 1_{\text {Edge }}, T 2_{\text {Edge }}$ are the first and the second threshold values for the edges of images, respectively. ${ }^{E d g e_{\text {mean }}}$, $E d g e_{\min }$ and $E d g e_{\max }$ are mean, min and max values of the grayscale color, respectively.

5) Threshold values of the black areas calculation: The plate images eroded by a small mask were compared with the image eroded by a large mask. The location of pixels with the same color values in P-06 of Fig. 5(g) and 5(h), the color value of the grayscale image of Fig. 5(a) and 5(b) in that the position were stored in the array Black, the threshold value of black areas was calculated by using the equation:

$T 1_{\text {Black }}=\operatorname{round}\left(\right.$ Black $_{\text {mean }}+$ sblack $)$ sblack $=a b s\left(\left(\right.\right.$ Black $_{\max }-$ Black $\left.\left._{\text {mean }}\right) / 2\right)$

where ${ }^{T 1_{\text {Black }}}$ is the threshold values for the black area of images, Black $_{\text {mean }}$ and Black $_{\max }$ are mean and max values of the grayscale color, respectively.

\section{B. Layer Separation Process}

1) Braille document images importing: A Braille document was imported by using the calibrated scanner from the previous step. They were color images in the RGB model converted to grayscale, the same as in step 2) of the previous process. Fig. 6(a) contains the background of the Braille document in P-01, the Braille embossed dot in P-02, and the typical character that was called a pattern shows in P-03.

2) Edges image calculation: The color values of the grayscale image in the pixel positions were compared with the threshold value of the edges derived from Equations (1) to (3). If the color values of the grayscale image in the pixel positions are between $T 1_{E d g e}$ and $T 2_{\text {Edge }}$ values, black color values were recorded in the white image for the edges image at the same pixel positions. The result was called the image of the edges, as shown in Fig. 6(b). It included the edges of the pattern shows in P-04, and the Braille embossed dots in P-05. There may be noise shown in P-06.

3) Black areas image calculation: The color values of the grayscale image in the pixel positions were compared with the threshold value of the black areas derived from Equation (4) and (5). If the color values of the grayscale image in the pixel positions were less than $T 1_{\text {Black }}$ values, black color values were recorded in the white image for the black area image at the same pixel positions. The result was called the image of the black areas, as shown in Fig. 6(c). It included the black areas of the pattern shows in P-07 and the holes of punctures in $\mathrm{P}-08$.
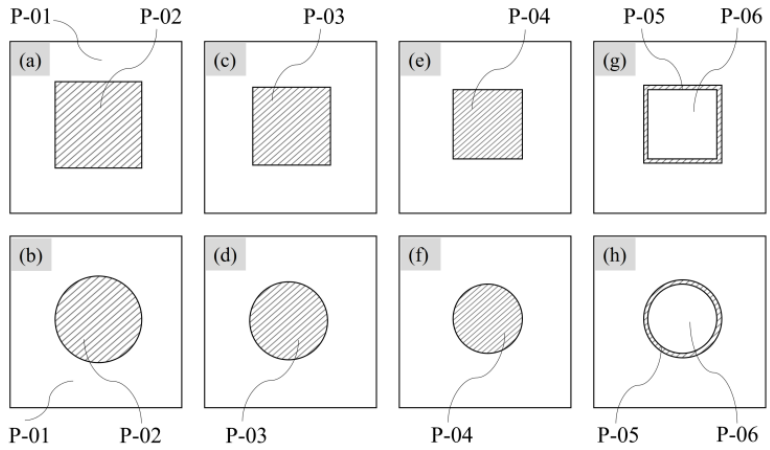

Fig. 5. Illustrations of the Scanner Calibration Process.

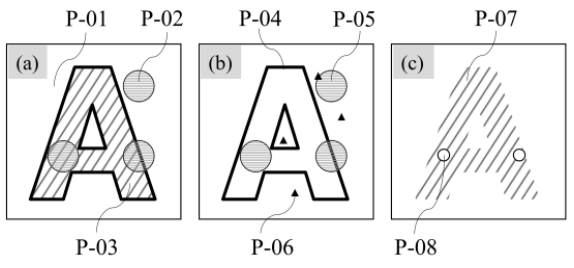

Fig. 6. Illustrations of the Layer Separation Process. 


\section{Edge Removal Process}

1) Image of the black areas dilation: The image results from the previous process as shown in Fig. 7(a). The black area's image was inverted color, the result is shown in Fig. 7(b). The black areas of the pattern were dilated with a mask. Then, the black areas that were larger and the holes of the puncture are filled, therefore the image of the black areas dilated, as shown in Fig. 7(c) and P-03 was larger than P-01 in Fig. 7(b).

2) Edges removed: The OR logic operation of the dilated black areas image shown in Fig. 7(c) and the image of the edges obtained in the previous process, Fig. 7(d), which can remove the edges of the pattern. In Fig. 7(e), the result is the image of the edges removed that still has Braille embossed dots in P-04 and P-06 and some noise in P-05, as shown in Fig. 7(e).

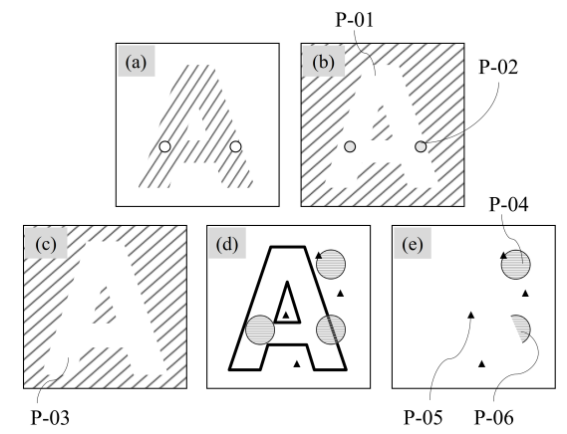

Fig. 7. Illustrations of the Edge Removal Process.

\section{Data Recovery Process}

1) Image of the black area's erosion: The inverted image of the black areas dilated from the previous process, Fig. 8(a), were eroded with a mask. In Fig. 8(b), the white areas are smaller than before. Fig. 8(c) showed the inverted color, called the image of the eroded black areas, which shown in P-01.

2) The braille dots recovery: The OR logic operation of the image of the black areas eroded, shown in Fig. 8(c), and the image of the edges, shown in Fig. 8(d), which can recover the details of the Braille embossed dot. And then, it was combined with the image of the edges, as shown in Fig. 8(e). The result was the image of removed edges and the details, as shown in Fig. 8(f), P-02 is the Braille embossed dot and P-03 is some noise.
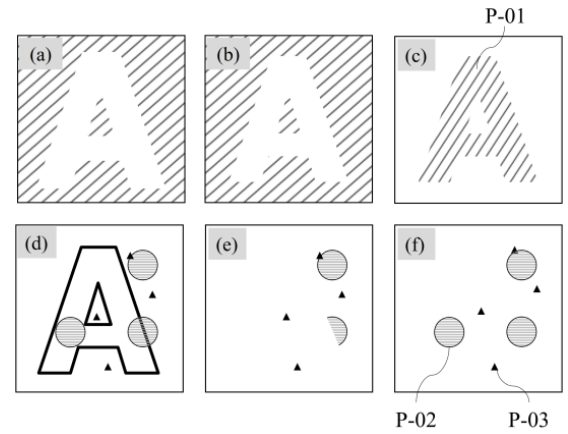

Fig. 8. Illustrations of the Data Recovery Process.

\section{E. Noise Removal Process}

1) Diffusion of the edges: The image of removed edges and details, Fig. 9(a), is exposed by a mask. The mask moves one pixel at a time to determine the color value. If the mask's center position was black value, it would be moved to a new position inside the mask. The black value with the new position was saved in the white image data. The result was the image of diffused edges as shown in Fig. 9(b), P-01 to P-03 are diffused dot and some noise.

2) Image enhancement: The images of diffused edges were applied by averaging filter, which created a clearer Braille embossed dot image. The result was an enhanced image as shown in Fig. 9(c).
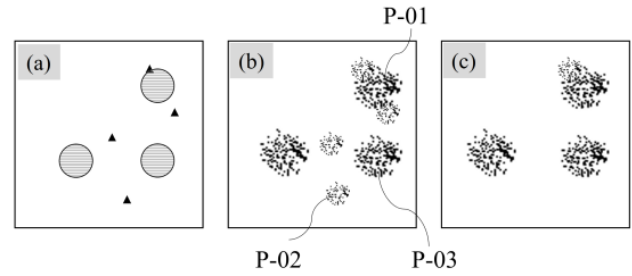

Fig. 9. Illustrations of the Noise Removal Process.

\section{F. Braille Localization Process}

1) Braille embossed dot dilation: The enhanced image, Fig. 10(a), was dilated by a mask. The result was a group of black values that were Braille embossed dots for more clarity as shown in Fig. 10(b).

2) The centroid of braille embossed dot: The group of black values in the previous step was calculated by connected component labeling. The result was the centroid of Braille embossed dot, which was a Braille embossed dots location as shown in P-01 of Fig. 10(c).
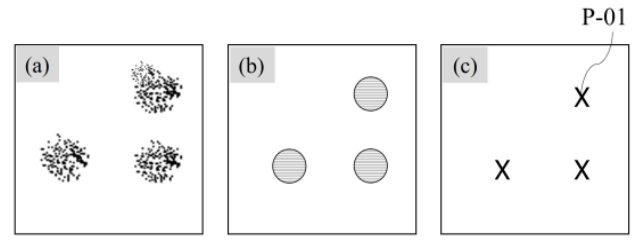

Fig. 10. Illustrations of the Braille Localization Process.

\section{EXPERIMENTS AND RESULTS}

\section{A. Dataset}

This research produced a dataset of Braille embossed dots named KU-Braille-Dot. Braille documents were produced on reusable paper by using slate and stylus. Consider Table I, this research created reusable paper by using an 80 GSM A4 paper to print text by using a LaserJet printer and Inkjet printer. It was then used to create Braille documents by using the slate and stylus. These Braille documents were scanned by using four scanners, each with different lighting environments, as shown in Fig. 11. The Braille document images had a resolution of $300 \mathrm{DPI}$. It is cropped to size $40 \times 40$ pixels under six events; each event contains 100 image data obtained from 50 images from the Inkjet printer and 50 images from LaserJet printer. The details of the six events were: (1) Event 1: Braille 
embossed dots were in the middle of any text, 100 images. (2) Event 2: Braille embossed dots overlap any text, but they were visible, 100 images. (3) Event 3: Braille embossed dots were on a plain background, 100 images. (4) Event 4: Braille embossed dots overlap any text, but they were not visible, 100 images. (5) Event 5: Plain background with no Braille embossed dot and no text, 100 images. (6) Event 6: Plain background with text and no Braille embossed dot, 100 images.

\section{B. Experimental Design}

The proposed method was tested by creating a single-cell Braille with various patterns from the KU-Braille-Dots dataset. A single-cell Braille contains six dot positions, each of which can occur in six events, so $6 \times 6 \times 6 \times 6 \times 6 \times 6$ is equal to 46,656 patterns in total. A dot position of Braille has six events. The events were arranged in order, and each event was a randomized image from 100 images, called a data group in the A form, as shown in Fig. 12. A single-cell Braille contained six dots, and therefore required six groups of data in the A form, which were sorted into a data group, called the B form, as shown in Fig. 13. Each row was a group of data in the A form relative to the dot positions of a single-cell Braille. A group of data in the B form which could create a single-cell Braille with 46,656 patterns.

This research created 150,000 groups of data in the A form. Each group had a unique event image or could contain no more than two duplicate event images. Those data were then randomly grouped into 262,144 groups in the B form, and each group had a unique arrangement of event images. That is, 262,144 cells Braille, which had 12,230,590,464 patterns.

TABLE I. DETAILS OF THE KU-BRAILLE-Dot DataseT

\begin{tabular}{|c|c|c|c|c|c|}
\hline Scanner & Event & $\begin{array}{l}\text { Number } \\
\text { of Images }\end{array}$ & Scanner & Event & $\begin{array}{l}\text { Number } \\
\text { of Images }\end{array}$ \\
\hline \multirow{6}{*}{$\begin{array}{l}\text { Light } \\
\text { Condition } \\
1\end{array}$} & Event 1 & 100 & \multirow{6}{*}{$\begin{array}{l}\text { Light } \\
\text { Condition } \\
2\end{array}$} & Event 1 & 100 \\
\hline & Event 2 & 100 & & Event 2 & 100 \\
\hline & Event 3 & 100 & & Event 3 & 100 \\
\hline & Event 4 & 100 & & Event 4 & 100 \\
\hline & Event 5 & 100 & & Event 5 & 100 \\
\hline & Event 6 & 100 & & Event 6 & 100 \\
\hline \multirow{6}{*}{$\begin{array}{l}\text { Light } \\
\text { Condition } \\
3\end{array}$} & Event 1 & 100 & \multirow{6}{*}{$\begin{array}{l}\text { Light } \\
\text { Condition } \\
4\end{array}$} & Event 1 & 100 \\
\hline & Event 2 & 100 & & Event 2 & 100 \\
\hline & Event 3 & 100 & & Event 3 & 100 \\
\hline & Event 4 & 100 & & Event 4 & 100 \\
\hline & Event 5 & 100 & & Event 5 & 100 \\
\hline & Event 6 & 100 & & Event 6 & 100 \\
\hline
\end{tabular}

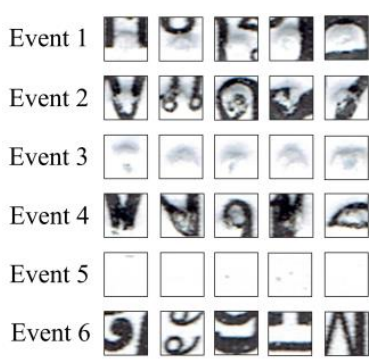

(a)

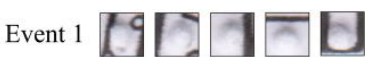

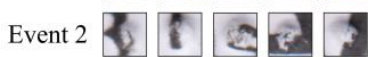
Event $3 \square \square \square \square \square$ Event 4 ด्ष Event 5 Event

(b)

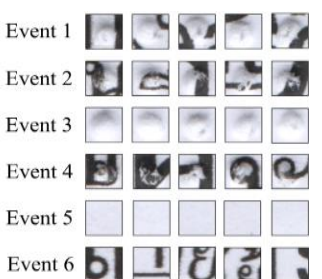

(c)

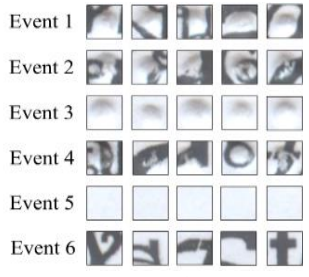

(d)
Fig. 11. Example of the KU-Braille-Dots: (a) Light Condition 1 (b) Light Condition 2 (c) Light Condition 3 and (d) Light Condition 4.

\begin{tabular}{|c|c|c|c|c|c|}
\hline Event 01 & Event 02 & Event 03 & Event 04 & Event 05 & Event 06 \\
\hline 35 & 32 & 4 & 96 & 21 & 57 \\
\hline
\end{tabular}

Fig. 12. An Example of the Data Group in a Form and the Index of Event Images.

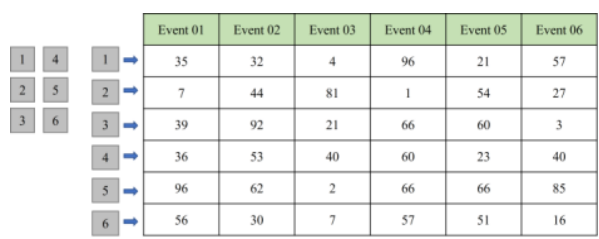

Fig. 13. A Group of Data in b Form.

TABLE II. The Number of BRAILle CELl INCREASES By 1 Times

\begin{tabular}{|l|l|l|l|}
\hline Group No. & Braille Cell & Group No. & Braille Cell \\
\hline 1 & 1 & 11 & 1,024 \\
\hline 2 & 2 & 12 & 2,048 \\
\hline 3 & 4 & 13 & 4,096 \\
\hline 4 & 8 & 14 & 8,192 \\
\hline 5 & 16 & 15 & 16,384 \\
\hline 6 & 32 & 16 & 32,768 \\
\hline 7 & 64 & 17 & 65,536 \\
\hline 8 & 128 & 18 & 131,072 \\
\hline 9 & 256 & 19 & 262,144 \\
\hline 10 & 512 & & \\
\hline
\end{tabular}

\section{Performance Measurement}

This research was to test the performance measurement of the proposed method using the number of the cell Braille increased by 1 times, starting from a single-cell Braille up to 262,144 cells Braille, as shown in Table II. The performance measurement of the proposed method, a single-cell Braille was used to describe, as shown in Fig. 14. The details were: (1) Consider the area No. 1, the gray area is the Braille embossed dots, and the white area is the background. (2) The ground truth of a single-cell Braille is shown in the area No. 3, the green area is the Braille embossed dots, and the blue area is the background. (3) In the area No. 2, the results are Braille embossed dots obtained from the proposed method. Positions 2, 3 and 5 are Braille embossed dots and the positions 1, 4 and 6 are non-Braille embossed dots or background. (4) Consider the results obtained from the proposed method and the ground truth. In area No. 4, positions 4 and 5 answered incorrectly. (5) This was used to evaluate the performance measurement of the proposed method by calculating Precision, Recall, Accuracy, and F-Measure, respectively. 


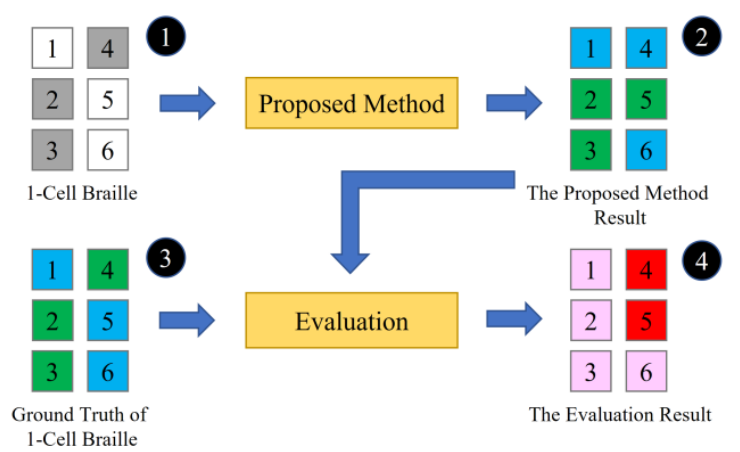

Fig. 14. The Diagram of the Performance Measurement.

\section{Results and Discussion}

The presented method was tested with the data sets described in the previous section. This research aimed to extract the Braille embossed dots from Braille documents created on reusable paper. An example of the calculation according to the proposed method using a single Braille embossed dot is shown in Fig. 15. These documents were scanned by using four flatbed scanners, videlicet, four lighting conditions. This research plotted graphs of the light condition as shown in Fig. 16 to 19, each of which has four lines representing Precision, Recall, Accuracy, and F-Measure, respectively, and has a value between 0.00 and 1.00 . The yaxis of the graph is the numerical measure, which is a value between 0.00 and 1.00 , but these graphs start plotting at a value of 0.6 for clarity. The $x$-axis of the graph is group No. of the Braille datasets used for testing.

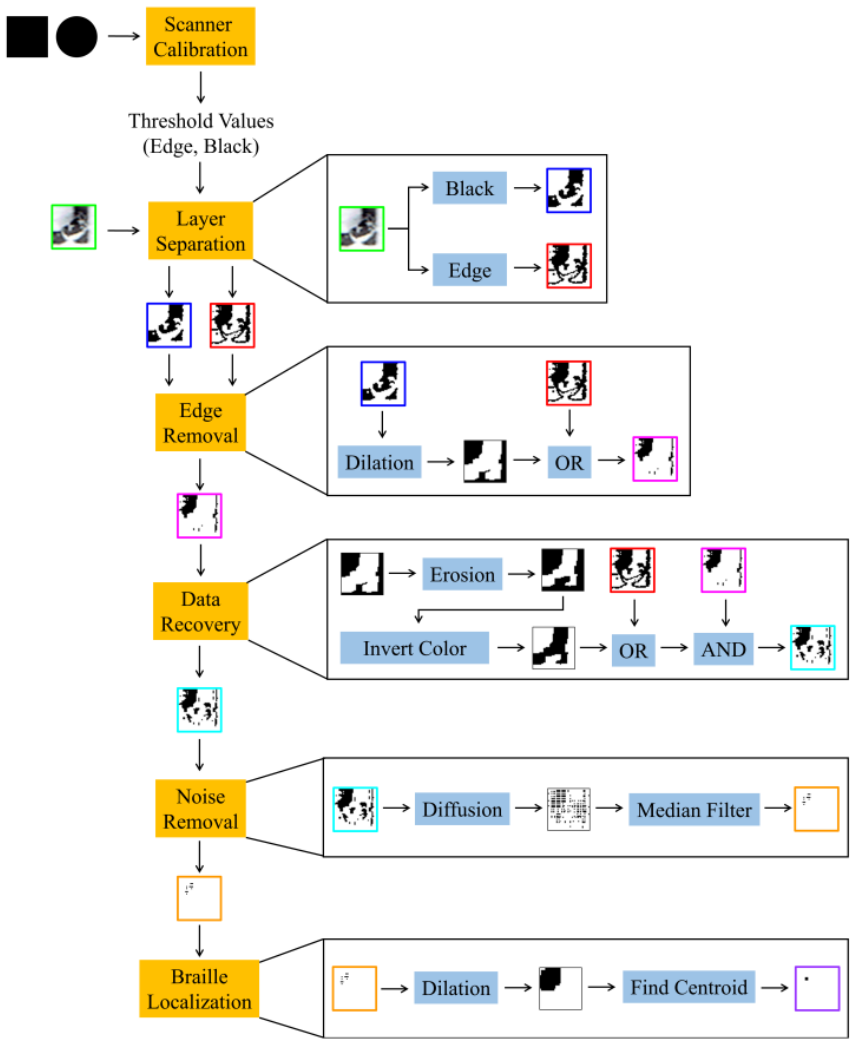

Fig. 15. The Schematic Diagram describes the Processing according to the Proposed Method.
Consider Fig. 16 to 19; in the Precision lines, the four lighting conditions have a Precision value of 1.00 . In the Recall lines, light conditions 1,2 , and 4 are approximately 0.80 , and light condition 3 is approximately 0.70 . The Accuracy lines in all light conditions are over 0.80 . In the F-measure lines calculated from Precision and Recall, each lighting condition is over 0.80 . When calculating the average performances in all lighting conditions, the values are Precision 1.0000, Recall 0.7817 , Accuracy 0.8545 , and F-Measure 0.8756 .

By considering the Accuracy and the F-measure values greater than 0.80 , it is known that there is approximately one position dot error in a single-cell Braille with six-position dots. This research is to extract Braille embossed dots on reusable paper. It is different from other research [1-15], which is only interested in Braille documents on plain paper.

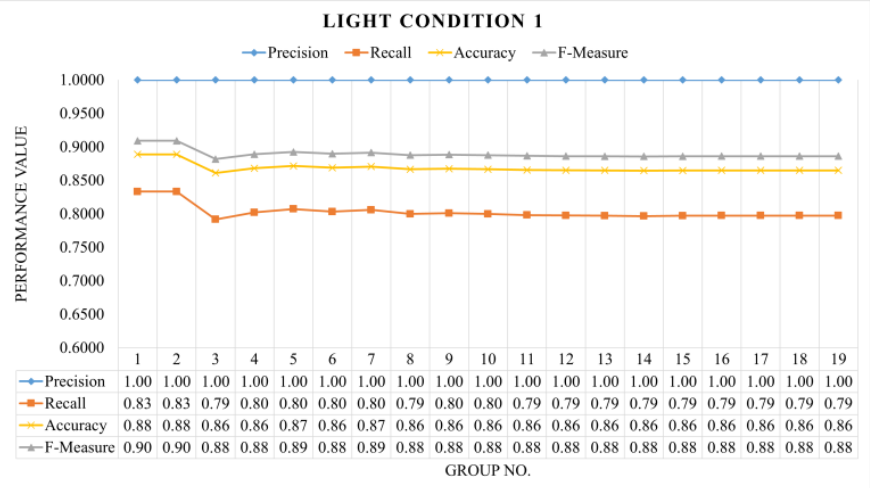

Fig. 16. The Performance Result for the Dataset in Light Condition 1.

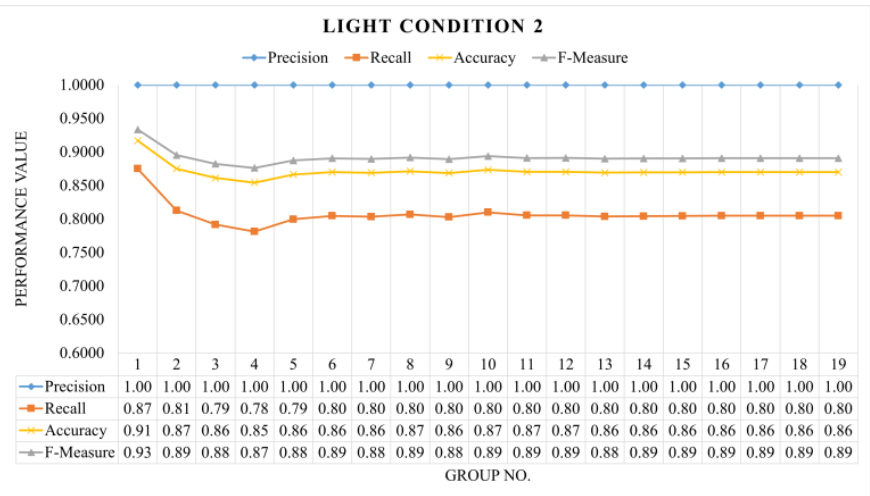

Fig. 17. The Performance Result for the Dataset in Light Condition 2.

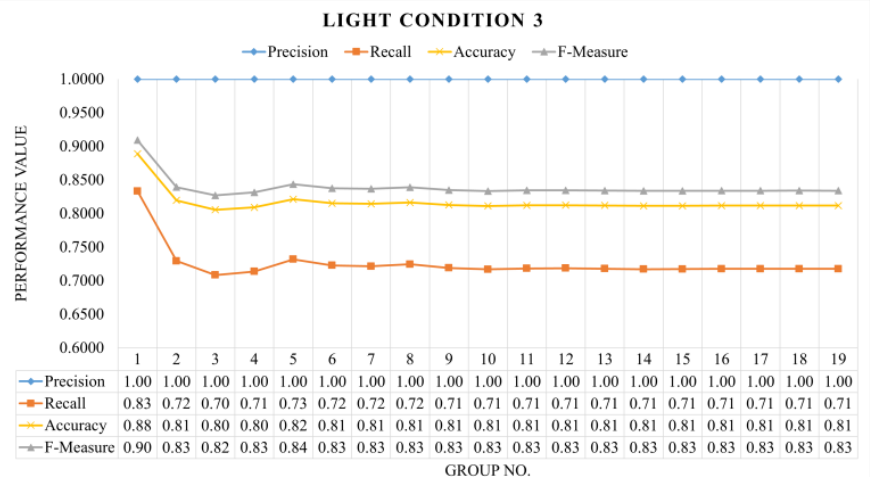

Fig. 18. The Performance Result for the Dataset in Light Condition 3. 


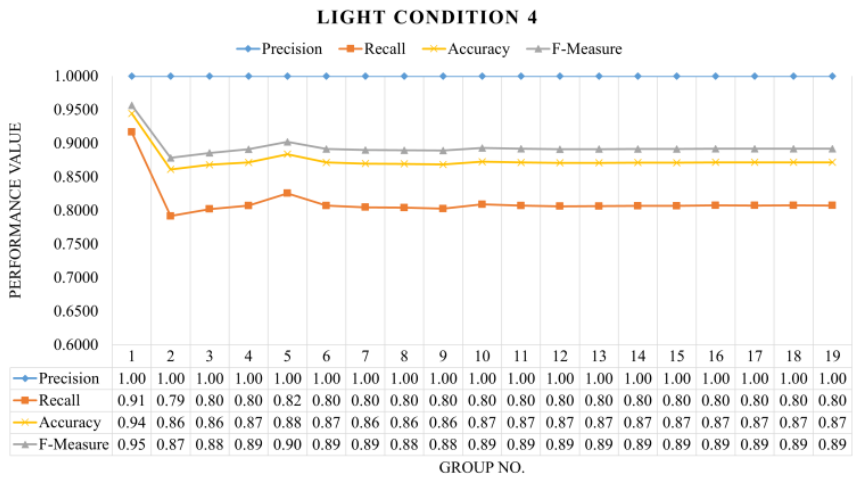

Fig. 19. The Performance Result for the Dataset in Light Condition 4.

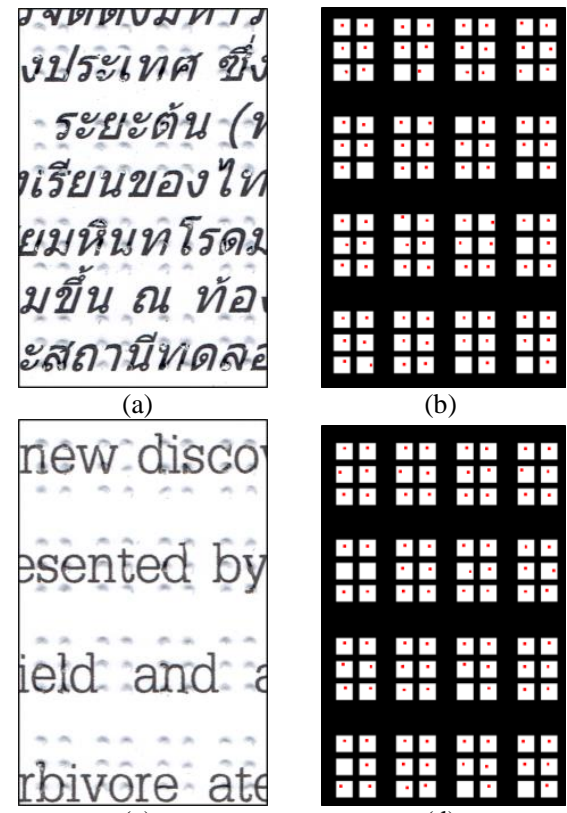

(c)

Fig. 20. Preliminary Experimental Results for the Proposed Method on KUBraille-Partial: (a) and (c) were Parts of a Braille Document Image. (b) and

(d) Resulted from the Proposed Method.

\section{CONCLUSION}

This paper presented the Braille embossed dots segmentation method for Braille document images that were tested as detailed. The results were good, with an average Accuracy and F-Measure of over 0.85 for all lighting conditions. This research confirmed that the proposed method has a good efficiency for Braille embossed dot segmentation for Braille documents produced on reusable paper, positively affecting the Braille recognition method.

The research included diverse flatbed scanner devices and lighting conditions. In this field of research, no research has been found on Braille documents produced on reusable paper. The methods presented here make the best use of paper resources and increase access to education for the blind. This research has opened a research path that is beneficial to the visually impaired or blind people to have more opportunities to study and learn.

\section{FUTURE WORK}

This research is a starting point to help create a digital document from documents created by the blind by using a slate and a stylus on reusable paper. It also facilitates communication between ordinary people and the blind or visually impaired and promotes the desire to be treated as ordinary. In the future, this method will be tested on the KUBraille-Partial dataset to achieve higher accuracy. Further developed methods are applied to actual Braille documents created on reusable paper. The KU-Braille-Partial was a dataset of parts of a Braille document image produced on reusable paper using slate and stylus. This research created reusable paper using an 80 GSM A4 paper to print text using a LaserJet printer and Inkjet printer. They were scanned by using four scanners with a resolution of 300 DPI. It was cropped to size $585 \times 915$ pixels - the sample images as shown in Fig. 20(a) and 20(c). The ground truth images were created-the sample images as shown in Fig. 20(b) and 20(d). The white rectangular areas were the Braille embossed dots, and the black areas were the non-Braille embossed dots. The red dot in the white square means that the proposed method was correct, but in other cases, it was wrong. The results obtained from this preliminary experiment showed that the proposed method was practical and that the research scale could be scaled up.

\section{ACKNOWLEDGMENT}

The authors wish to thank the many people for their contribution to this project; Ms. Chavee Tiendee, Ms. Chatchada Nanto, Ms. Pranom Sirimangkalo, Ms. Benjamas Toumbumrung, and Ms. Kwanruethai Naksongkaew, for their help in creating the Braille document dataset. Special thanks should be given to Kasetsart University for the Ph.D. scholarship.

\section{REFERENCES}

[1] C. M. Ng, V. Ng, and Y. Lau, "Regular feature extraction for recognition of Braille," in Proceedings Third International Conference on Computational Intelligence and Multimedia Applications. ICCIMA'99 (Cat. No.PR00300), 23-26 Sept. 1999 1999, pp. 302-306, doi: 10.1109/ICCIMA.1999.798547.

[2] A. Al-Saleh, A. El-Zaart, and A. Alsalman, "Dot Detection of Optical Braille Images for Braille Cells Recognition," presented at the Proceedings of the 11th international conference on Computers Helping People with Special Needs, linz, Austria, 2008. [Online]. Available: https://doi.org/10.1007/978-3-540-70540-6_122.

[3] A. S. Al-Salman, A. El-Zaart, Y. Al-Suhaibani, K. Al-Hokail, and A. O. Al-Qabbany, "An Efficient Braille Cells Recognition," in 2010 6th International Conference on Wireless Communications Networking and Mobile Computing (WiCOM), 23-25 Sept. 2010 2010, pp. 1-4, doi: 10.1109/WICOM.2010.5601020.

[4] A.-S. Amany, E.-Z. Ali, and A.-S. Abdul Malik, "Dot Detection of Braille Images Using A Mixture of Beta Distributions," Journal of Computer Science, vol. 7, no. 11, 09/06 2011, doi: 10.3844/jcssp.2011.1749.1759.

[5] M. Y. Babadi and S. Jafari, "Novel grid-based optical Braille conversion: from scanning to wording," International Journal of Electronics, vol. 98, no. 12, pp. 1659-1671, 2011/12/01 2011, doi: 10.1080/00207217.2011.609975.

[6] A. AlSalman, A. El-Zaart, S. Al-Salman, and A. Gumaei, "A novel approach for Braille images segmentation," in 2012 International Conference on Multimedia Computing and Systems, 10-12 May 2012 2012, pp. 190-195, doi: 10.1109/ICMCS.2012.6320146.

[7] J. Mennens, L. V. Tichelen, G. Francois, and J. J. Engelen, "Optical recognition of Braille writing using standard equipment," IEEE 
Transactions on Rehabilitation Engineering, vol. 2, no. 4, pp. 207-212, 1994, doi: 10.1109/86.340878.

[8] L. Wong, W. Abdulla, and S. Hussmann, "A software algorithm prototype for optical recognition of embossed Braille," in Proceedings of the 17th International Conference on Pattern Recognition, 2004. ICPR 2004., 26-26 Aug. 2004 2004, vol. 2, pp. 586-589 Vol.2, doi: 10.1109/ICPR.2004.1334316.

[9] L. Jie and Y. Xiaoguang, "Optical Braille character recognition with Support-Vector Machine classifier," in 2010 International Conference on Computer Application and System Modeling (ICCASM 2010), 22-24 Oct. 2010 2010, vol. 12, pp. V12-219-V12-222, doi: 10.1109/ICCASM.2010.5622245.

[10] L. Jie, Y. Xiaoguang, and Z. Dayong, "Optical Braille recognition with Haar wavelet features and Support-Vector Machine," in 2010 International Conference on Computer, Mechatronics, Control and Electronic Engineering, 24-26 Aug. 2010 2010, vol. 5, pp. 64-67, doi: 10.1109/CMCE.2010.5610062.

[11] B.-M. Hsu, "Braille Recognition for Reducing Asymmetric Communication between the Blind and Non-Blind," Symmetry, vol. 12, no. 7, p. 1069, 2020. [Online]. Available: https://www.mdpi.com/20738994/12/7/1069.

[12] A. AlSalman, A. Gumaei, A. AlSalman, and S. Al-Hadhrami, "A Deep Learning-Based Recognition Approach for the Conversion of Multilingual Braille Images," Computers, Materials $\backslash \&$ Continua, vol. 67, no. 3, 2021, doi: 10.32604/cmc.2021.015614.

[13] M. Y. Babadi, B. Nasihatkon, Z. Azimifar, and P. Fieguth, "Probabilistic estimation of Braille document parameters," in 2009 16th IEEE International Conference on Image Processing (ICIP), 7-10 Nov. 2009 2009, pp. 2001-2004, doi: 10.1109/ICIP.2009.5413816.

[14] M. Yousefi, M. Famouri, B. Nasihatkon, Z. Azimifar, and P. Fieguth, "A robust probabilistic Braille recognition system," International Journal on Document Analysis and Recognition (IJDAR), vol. 15, no. 3, pp. 253266, 2012/09/01 2012, doi: 10.1007/s10032-011-0171-7.

[15] H. Kawabe, Y. Shimomura, H. Nambo, and S. Seto, "Application of Deep Learning to Classification of Braille Dot for Restoration of Old Braille Books," in Proceedings of the Twelfth International Conference on Management Science and Engineering Management, Cham, J. Xu, F. L. Cooke, M. Gen, and S. E. Ahmed, Eds., 2019// 2019: Springer International Publishing, pp. 913-926.

[16] A. Delaye and C.-L. Liu, "Contextual text/non-text stroke classification in online handwritten notes with conditional random fields," Pattern Recognition, vol. 47, no. 3, pp. 959-968, 2014/03/01/ 2014, doi: https://doi.org/10.1016/j.patcog.2013.04.017.

[17] S. S. Bukhari, Z. Iftikhar, and A. Dengel, "Chemical Structure Recognition (CSR) System: Automatic Analysis of 2D Chemical Structures in Document Images," in 2019 International Conference on Document Analysis and Recognition (ICDAR), 20-25 Sept. 2019 2019, pp. 1262-1267, doi: 10.1109/ICDAR.2019.00-41.

[18] B. H. Phong, T. M. Hoang, and T. L. Le, "A Hybrid Method for Mathematical Expression Detection in Scientific Document Images," IEEE Access, vol. 8, pp. 83663-83684, 2020, doi: 10.1109/ACCESS.2020.2992067.

[19] S. Elaiwat and M. Abu-Zanona, "Arabic Word Recognition System for Historical Documents using Multiscale Representation Method," International Journal of Advanced Computer Science and Applications, vol. 11, no. 4, 2020 2020, doi: 10.14569/IJACSA.2020.01104107.

[20] D. P. Van Hoai, H.-T. Duong, and V. T. Hoang, "Text recognition for Vietnamese identity card based on deep features network," International Journal on Document Analysis and Recognition (IJDAR), vol. 24, no. 1, pp. 123-131, 2021/06/01 2021, doi: 10.1007/s10032-021-00363-7.
[21] A. M.Hesham, S. Abdou, A. Badr, M. Rashwan, and H. M.AlBarhamtoshy, "A Zone Classification Approach for Arabic Documents using Hybrid Features," International Journal of Advanced Computer Science and Applications, vol. 7, no. 7, 2016 2016, doi: 10.14569/IJACSA.2016.070722.

[22] J. Calvo-Zaragoza, K. Zhang, Z. Saleh, G. Vigliensoni, and I. Fujinaga, "Music Document Layout Analysis through Machine Learning and Human Feedback," in 2017 14th IAPR International Conference on Document Analysis and Recognition (ICDAR), 9-15 Nov. 2017 2017, vol. 02, pp. 23-24, doi: 10.1109/ICDAR.2017.259.

[23] S. T. R. Rizvi, A. Dengel, and S. Ahmed, "A Hybrid Approach and Unified Framework for Bibliographic Reference Extraction," IEEE Access, vol. 8, pp. 217231-217245, 2020, doi: 10.1109/ACCESS.2020.3042455.

[24] R. Arief, A. B. Mutiara, T. M. Kusuma, and Hustinawaty, "Automated Extraction of Large Scale Scanned Document Images using Google Vision OCR in Apache Hadoop Environment," International Journal of Advanced Computer Science and Applications, vol. 9, no. 11, 2018 2018, doi: 10.14569/IJACSA.2018.091117.

[25] Y. Liu, C. Si, K. Jin, T. Shen, and M. Hu, "FCENet: An Instance Segmentation Model for Extracting Figures and Captions From Material Documents," IEEE Access, vol. 9, pp. 551-564, 2021, doi: 10.1109/ACCESS.2020.3046496.

[26] A. Zhu, C. Zhang, Z. Li, and S. Xiong, "Coarse-to-fine document localization in natural scene image with regional attention and recursive corner refinement," International Journal on Document Analysis and Recognition (IJDAR), vol. 22, no. 3, pp. 351-360, 2019/09/01 2019, doi: 10.1007/s10032-019-00341-0.

[27] D.-D. Nguyen, "TableSegNet: a fully convolutional network for table detection and segmentation in document images," International Journal on Document Analysis and Recognition (IJDAR), 2021/11/22 2021, doi: 10.1007/s10032-021-00390-4.

[28] P. D. Ingle and P. Kaur, "Adaptive thresholding to robust image binarization for degraded document images," in 2017 1st International Conference on Intelligent Systems and Information Management (ICISIM), 5-6 Oct. 2017 2017, pp. 189-193, doi: 10.1109/ICISIM.2017.8122172.

[29] F. Drira and F. LeBourgeois, "Mean-Shift segmentation and PDE-based nonlinear diffusion: toward a common variational framework for foreground/background document image segmentation," International Journal on Document Analysis and Recognition (IJDAR), vol. 20, no. 3, pp. 201-222, 2017/09/01 2017, doi: 10.1007/s10032-017-0285-7.

[30] M. Hanif, A. Tonazzini, P. Savino, and E. Salerno, "Non-Local Sparse Image Inpainting for Document Bleed-Through Removal," Journal of Imaging, vol. 4, no. 5, p. 68, 2018. [Online]. Available: https://www.mdpi.com/2313-433X/4/5/68.

[31] D. Rodin, A. Zharkov, and I. Zagaynov, "Faster Glare Detection on Document Images," in Document Analysis Systems, Cham, X. Bai, D. Karatzas, and D. Lopresti, Eds., 2020// 2020: Springer International Publishing, pp. 161-167.

[32] J. R. Wang and Y. Y. Chuang, "Shadow Removal of Text Document Images by Estimating Local and Global Background Colors," in ICASSP 2020 - 2020 IEEE International Conference on Acoustics, Speech and Signal Processing (ICASSP), 4-8 May 2020 2020, pp. 15341538, doi: 10.1109/ICASSP40776.2020.9053378.

[33] C.-M. Tsai, "Intelligent region-based thresholding for color document images with highlighted regions," Pattern Recogn., vol. 45, no. 4, pp. 1341-1362, 2012, doi: 10.1016/j.patcog.2011.09.024. 